\title{
HUBUNGAN PERILAKU DENGAN KUALITAS KOMPONEN RUMAH PENDERITA PENYAKIT INFEKSI SALURAN PERNAPASAN AKUT TAHUN 2017 (Studi Kasus di Desa Wage Kecamatan Taman Kabupaten Sidoarjo)
}

\author{
Dana Aprilia, Umi Rahayu, Imam Khambali
}

\begin{abstract}
Bad behavior of maintaining the quality of house components can be a risk factor to environmentally based disease transmission. a.o, Acute Respiration Infection. The germs of Acute Respiration Infection can be transmitted through coughing or sneezing using air as transmission media. This research aimed to find out the relation between behavior and the quality of house component of people affected by acute respiration infection.

This research was analytical with cross sectional approach. Data collection was through observation, interviews and measurements. Sample collected were 51 houses of people suffering from Acute Respiration Infection. Variables of this research were: awareness, behavior, action / proceeding, ventilation available, lighting, humidity, temperature, bedroom occupants density, and cleanliness of the house. Sampling technique used was random sampling. Data analyzes utilized was Chi Square test statistical analysis by means of SPSS 20 version.

The result of the research showed that there was a relation between awareness $(p=0,005)$, attitude $(p=0,032)$, action/proceeding $(p=0,002)$ behavior $(p=0,002)$ with the quality of house components of people affected by Acute Respiration Infection.

Based on this research, it could be concluded that there was a relation between awareness level, attitude, proceeding, and behavior with the quality of house component of people affected by Acute Respiration Infection. Prevention of transmission of Acute Respiration Infection could be done by upgrading the patient and house inmates behavior to create a healthy house condition.
\end{abstract}

Keywords : Behavior, Quality of the House Components, Acute Respiration Infection

\section{PENDAHULUAN}

Rumah merupakan salah satu bagian dari lingkungan yang sangat berpengaruh dalam kejadian suatu penyakit (Permenkes RI No. 1077 Tahun 2011 dalam Lingga. dkk, 2014). Kondisi rumah yang kurang memenuhi syarat berisiko menjadi sumber penularan berbagai penyakit, khususnya penyakit berbasis lingkungan (Noriwadziyah. dkk, 2013). Salah satunya ialah penyakit ISPA. ISPA adalah infeksi akut yang menyerang salah satu bagian atau lebih saluran pernapasan yang berlangsung selama 14 hari.

Sesuai data yang diperoleh dari Puskesmas Pembantu Wage, penyakit 
ISPA merupakan penyakit terbanyak di tahun 2015 dengan total 951 kasus. Pada tahun 2016 masih tercatat sebagai kasus paling banyak yaitu 583 kasus (periode Januari-September 2016).

Peneliti melakukan survei awal pada tanggal 15 November 2016 ke10 rumah penderita ISPA di Desa Wage Kecamatan Taman Kabupaten Sidoarjo. Kualitas komponen rumah yang diperiksa memiliki kondisi yang kurang sehat dan perilaku yang kurang baik. Terbukti bahwa ventilasi tertutup rapat sehingga pertukaran udara segar dan udara kotor tidak dapat

berlangsung dengan baik. Pencahayaan yang dimiliki penderita kurang (rata-rata 30 lux) akan mempengaruhi kelembaban dan suhu ruangan. Kondisi ini mengakibatkan kualitas udara kurang baik, sehingga dapat menjadi sumber risiko penularan penyakit, salah satunya ialah penyakit ISPA.

Faktor lain ialah kepadatan penghuni dalam kamar tidur yang tidak sebanding dengan luas lantai kamar. Terlihat bahwa kamar tidur dihuni lebih dari 2 orang dewasa dan anak berumur lebih dari 5 tahun yang akan menimbulkan dampak negatif bagi kesehatan. Perilaku penderita ISPA meliputi pengetahuan dan tindakan tentang kualitas komponen rumah dikatakan kurang baik. Kurangnya pengetahuan dapat berpengaruh dalam menjaga kualitas komponen rumah. Tindakan kurang diterapkan seperti tidak menggunakan masker dan tidak menutup mulut ketika batuk maupun bersin. Kondisi tersebut dapat mengakibatkan penularan penyakit, salah satunya ialah penyakit ISPA karena penyakit tersebut erat kaitannya dengan rumah yang kurang sehat. Pencegahan penularan penyakit ISPA dapat dilakukan dengan meningkatkan perilaku penderita dan anggota keluarga untuk menciptakan kondisi rumah yang sehat.

Penelitian ini bertujuan untuk mengetahui hubungan antara perilaku dan kualitas komponen rumah orang yang terkena infeksi pernapasan akut.

\section{METODE PENELITIAN}

Penelitian ini termasuk
penelitian analitik dengan desain
penelitian cross sectional. Lokasi
penelitian di Desa Wage Kecamatan
Taman Kabupaten Sidoarjo yaitu pada
RW 01, RW 05, RW 06, RW 07, dan
RW 09. Sampel yang diambil dalam
penelitian ini sebanyak 51 rumah.

Teknik pengambilan sampel ini menggunakan metode Simple Random Sampling. Teknik pengumpulan data dilakukan dengan cara wawancara, observasi, dan pengukuran. Analisis data menggunakan analisis statistik dengan uji Chi square. Kemudian dilanjutkan dengan uji Coefficient Contingency untuk mengukur keeratan hubungan antara 2 variabel.

\section{HASIL DAN PEMBAHASAN}

\section{A. Hasil Penilaian Tingkat \\ Pengetahuan Penderita ISPA Tahun 2017}

Hasil penilaian tingkat pengetahuan penderita penyakit ISPA dengan kriteria baik $=70 \%-100 \%$, cukup $=36,67 \%-69,99 \%$, dan kurang $=33,67 \%$ adalah sebagai berikut. 
Berdasarkan tabel.1 dapat

diketahui bahwa penderita yang memiliki tingkat pengetahuan baik sebanyak 6 orang $(11,08 \%)$, tingkat pengetahuan cukup sebanyak 16 orang $(31,4 \%)$, dan tingkat pengetahuan kurang sebanyak 29 orang $(56,9 \%)$. Dalam hasil kuisioner, jawaban yang kurang tepat didominasi pada pertanyaan mengenai pembuatan ventilasi \& fungsinya, menjaga kebersihan rumah yang baik dan kelembaban yang memenuhi syarat kesehatan. Sebagian besar penderita memilih jawaban pembuatan ventilasi diletakkan sejajar $(56,9 \%)$ dan fungsi ventilasi jarang dibuka $(66,7 \%)$, waktu membersihkan rumah yang baik yaitu satu hari sekali (72,5\%), dan ukuran kelembaban yang baik adalah rendah $(68,6 \%)$.

Salah satu faktor yang mempengaruhi pengetahuan adalah tingkat pendidikan. Dilihat dari hasil wawancara, pengetahuan yang dimiliki penderita sebagian besar kurang. Hal ini dapat terjadi karena tingkat pendidikan terakhir mereka adalah SD $(41,17 \%)$ sehingga dapat mempengaruhi tingkat pengetahuannya. Semakin rendah pengetahuan, maka upaya untuk menjaga kualitas komponen rumahnya kurang baik. Namun sebaliknya, apabila semakin tinggi pengetahuan, harapannya dalam menjaga kualitas komponen rumahnya juga semakin baik.

Saran yang dapat diberikan oleh peneliti yaitu lebih meningkatkan pengetahuannya mengenai persyaratan komponen rumah untuk mencegah terjadinya penularan penyakit ISPA, seperti luas ventilasi, pencahayaan, kelembaban, suhu, kepadatan penghuni dalam kamar tidur yang memenuhi syarat kesehatan, dan menjaga kebersihan rumah yang baik. Selain itu perlunya menjaga kesehatan gizi seimbang dengan mengonsumsi makanan sehat. Hal tersebut dapat dilakukan dengan cara mengikuti penyuluhan, mencari informasi melalui media cetak/eletronik seperti buku, majalah radio, dan televisi.

\section{B. Hasil Penilaian Sikap Penderita Penyakit ISPA Tahun 2017}

Hasil penilaian sikap penderita penyakit ISPA dengan kriteria baik $=81,1 \%-100 \%$, cukup $=36,67 \%-$ $69,99 \%$, dan kurang $=<58,87 \%$, adalah sebagai berikut.

\section{Tabel.2}

DISTRIBUSI FREKUENSI SIKAP PENDERITA PENYAKIT ISPA TAHUN 2017

\begin{tabular}{|l|l|c|r|}
\hline \multirow{2}{*}{ No. } & \multirow{2}{*}{ Sikap } & \multicolumn{2}{|c|}{ Penderita } \\
\cline { 3 - 4 } & & $\begin{array}{c}\text { Jumla } \\
\text { h }\end{array}$ & (\%) \\
\hline 1. & Baik & 6 & $11,8 \%$ \\
\hline 2. & Cukup & 17 & $33,3 \%$ \\
\hline 3. & Kurang & 28 & $54,9 \%$ \\
\hline & Jumlah & 51 & $100 \%$ \\
\hline
\end{tabular}


Berdasarkan tabel.2 dapat diketahui bahwa penderita yang memiliki sikap baik sebanyak 6 orang $(11,8 \%)$, sikap cukup sebanyak 17 orang $(33,3 \%)$, dan sikap kurang sebanyak 28 orang (54,9\%).

Dalam hasil kuisioner, jawaban tidak setuju didominasi pada pertanyaan membuka jendela dipagi hari dalam mencegah perkembang biakan kuman penyebab penyakit ISPA $(62,7 \%)$ dan menutup mulut ketika batuk maupun bersin $(70,6 \%)$. Sebagian besar penderita tidak setuju dalam membuka jendela dipagi hari karena kesibukan mereka diluar rumah. Selain itu, karena penderita takut apabila ada orang lain masuk atau adanya binatang pengganggu dalam rumah. Salah satu faktor yang menyebabkan kurangnya sikap yang dimiliki penderita yaitu tingkat pengetahuan yang juga kurang.

Saran yang dapat diberikan oleh peneliti yaitu menambah ilmu pengetahuan mengenai persyaratan komponen rumah meliputi ventilasi, pencahayaan, kelembaban, suhu, kepadatan penghuni dalam kamar tidur yang memenuhi syarat kesehatan, dan menjaga kebersihan rumah yang baik untuk mencegah penularan penyakit ISPA. Hal ini dapat dilakukan melalui penyuluhan, mencari informasi melalui media cetak/eletronik seperti membaca buku, melihat televisi sehingga penderita dapat mengubah sikapnya menjadi lebih baik.

\section{Hasil Penilaian Tindakan Penderita Penyakit ISPA Tahun 2017}

Hasil penilaian tindakan penderita penyakit ISPA dengan kriteria baik = $81,1 \%-100 \%$, cukup $=36,67 \%-69,99 \%$, dan kurang $=<17,66$ atau $<58,87 \%$ adalah sebagai berikut.

\section{Tabel.3}

DISTRIBUSI FREKUENSI TINDAKAN PENDERITA ISPA TAHUN 2017

\begin{tabular}{|r|l|c|c|}
\hline \multirow{2}{*}{ No. } & \multirow{2}{*}{} & Tindakan & \multicolumn{2}{|c|}{ Penderita } \\
\cline { 3 - 4 } & Jumlah & $(\%)$ \\
\hline 1. & Baik & 5 & $9,8 \%$ \\
\hline 2. & Cukup & 19 & $37,3 \%$ \\
\hline 3. & Kurang & 27 & $52,9 \%$ \\
\hline & Jumlah & 51 & $100 \%$ \\
\hline
\end{tabular}

Berdasarkan tabel.3 dapat diketahui bahwa penderita yang memiliki tindakan baik sebanyak 5 orang $(9,8 \%)$, cukup sebanyak 19 orang $(37,3 \%)$, dan kurang sebanyak 27 orang (52,9\%). Dalam hasil kuisioner, jawaban tidak didominasi pada pertanyaan tidur terpisah dengan orang sehat dalam satu kamar $(66,7 \%)$, menyapu mengepel lantai pada pagi dan sore $(60,8 \%)$ serta membuka jendela setiap pagi hari $(66,7 \%)$. Sebagian besar penderita tidur bersama orang sehat karena mereka memiliki luas kamar yang telah memenuhi syarat sehingga penderita tidak khawatir apabila tidur dengan orang sehat. Kondisi tersebut kurang baik karena meskipun luas kamar telah memenuhi syarat tetapi risiko penularan penyakit ke orang yang sehat dapat terjadi. Pencegahan penularan penyakit dapat dilakukan dengan cara tidak tidur bersama dengan orang sehat agar penderita segera memperoleh kesembuhan dan orang sehat tersebut tidak tertular 
penyakit. Menyapu dan mengepel pada pagi dan sore hari sangat dianjurkan karena debu yang menumpuk akan menyebabkan gangguan kesehatan, seperti alergi maupun penyakit pernapasan lainnya (Maryani, 2012:22).

\section{Hasil Penilaian Kualitas Komponen Rumah Penderita Penyakit ISPA Tahun 2017}

Hasil penilaian kualitas
komponen rumah penderita
penyakit ISPA dengan kriteria tidak
memenuhi syarat apabila $<52,17$
dan memenuhi syarat apabila
$52,17-100 \%$ adalah sebagai berikut.

Tabel IV.4

DISTRIBUSI FREKUENSI KUALITAS KOMPONEN RUMAH

DI DESA WAGE TAHUN 2017

\begin{tabular}{|r|l|r|r|}
\hline No. & $\begin{array}{l}\text { Kualitas } \\
\text { Komponen } \\
\text { Rumah }\end{array}$ & $\Sigma$ & (\%) \\
\hline 1. & $\begin{array}{l}\text { Tidak } \\
\text { memenuhi } 36 \\
\text { syarat }\end{array}$ & $70,6 \%$ & \\
\hline 2. & $\begin{array}{l}\text { Memenuhi } \\
\text { syarat }\end{array}$ & 15 & $29,4 \%$ \\
\hline & Jumlah & 51 & $100 \%$ \\
\hline
\end{tabular}

Berdasarkan tabel.4 dapat diketahui bahwa kualitas komponen rumah penderita yang tidak memenuhi syarat sebanyak 36 rumah $(70,6 \%)$ dan yang memenuhi syarat sebanyak 15 rumah $(29,4 \%)$. Kualitas komponen rumah yang kurang memenuhi syarat seperti ventilasi, pencahayaan, kelembaban, suhu, dan kebersihan rumah. Ventilasi yang tidak memenuhi syarat disebabkan karena luas ventilasi $<10 \%$ luas lantai, tidak dapat dibuka karena terhalang oleh benda lain, serta tidak cross ventilation sehingga pertukaran udara dalam rumah kurang lancar dan menyebabkan kelembaban naik, dimana kelembaban merupakan media yang baik untuk perkembangbiakan bakteri (Hutapea, 2013).

Pencahayaan yang kurang memenuhi syarat karena luas ventilasi yang kurang yang mengakibatkan pencahayaan yang diterima juga kurang dan fungsi ventilasi yang tidak dilakukan dengan baik. $\mathrm{Hal}$ ini menyebabkan ruangan di dalam rumah menjadi gelap sehingga kurang baik untuk membaca dan keadaan rumah yang lembab sehingga kuman dapat berkembangbiak.

Suhu yang kurang memenuhi syarat karena ventilasi tidak berfungsi dengan baik, pencahayaan dan kelembaban yang kurang memenuhi syarat sehingga akan menjadi media yang baik untuk tumbuh dan

berkembangnya mikroorganisme patogen.

Kebersihan rumah yang kurang memenuhi syarat terjadi karena kesibukan mereka yang sangat padat sehingga lantai, dinding, langit dan jendela/ventilasi masih terdapat debu dan kotoran. Keadaan rumah yang kotor dapat menjadi salah satu risiko terjadinya penularan penyakit. Namun demikian beberapa penderita telah memenuhi syarat kesehatan yaitu memiliki keadaan rumah yang bersih meliputi lantai, dinding, langit-langit, dan jendela/ventilasi. Rumah yang bersih dapat menghindarkan 
penghuninya dari penyakit seperti ISPA, TBC, maupun alergi.

\section{E. Hubungan Tingkat Pengetahuan Dengan Komponen Rumah Penderita ISPA}

Hasil penilaian tingkat pengetahuan dengan komponen rumah penderita penyakit ISPA di Desa Wage Kecamatan Taman Kabupaten Sidoarjo Tahun 2017 sebagai berikut.

Tabel.5

HUBUNGAN TINGKAT PENGETAHUAN DENGAN KUALITAS

KOMPONEN RUMAH PENDERITA PENYAKIT ISPA DI DESA WAGE

KECAMATAN TAMAN KABUPATEN SIDOARJO

\begin{tabular}{|c|c|c|c|c|c|c|c|}
\hline \multirow{2}{*}{ No. } & \multirow{2}{*}{$\begin{array}{c}\text { Tingkat } \\
\text { Pengetahuan }\end{array}$} & \multicolumn{4}{|c|}{$\begin{array}{l}\text { Kualitas Komponen } \\
\text { Rumah }\end{array}$} & \multirow{2}{*}{ Sig. } & \multirow{2}{*}{ Value } \\
\hline & & TMS & (\%) & MS & (\%) & & \\
\hline 1. & Baik & 1 & $16,7 \%$ & 5 & $83,3 \%$ & \multirow{4}{*}{0,005} & \multirow{4}{*}{0,403} \\
\hline 2. & Cukup & 11 & $68,8 \%$ & 5 & $31,2 \%$ & & \\
\hline 3. & Kurang & 24 & $82,8 \%$ & 5 & $17,2 \%$ & & \\
\hline & Jumlah & 36 & $70,6 \%$ & 15 & $29,4 \%$ & & \\
\hline
\end{tabular}

Berdasarkan tabel.5 dapat diketahui bahwa penderita yang memiliki tingkat pengetahuan baik dengan kualitas komponen rumah tidak memenuhi syarat sebanyak 1 $(16,7 \%)$ dan yang memenuhi syarat sebanyak 5 (83,3\%). Hal ini dikarenakan penderita yang memiliki tingkat pengetahuan baik tidak menerapkan hasil pengetahuannya untuk memelihara komponen rumah agar tetap terjaga kualitasnya, seperti luas ventilasinya yang $<10 \%$ luas lantai, tidak bisa dibuka dan ditutup, dan tidak cross ventilation sehingga pertukaran didalam rumah tidak lancar serta pencahayaan yang diterima juga kurang.

Selain itu, penderita yang tidak rutin dalam membersihkan rumahnya pada pagi dan sore hari sehingga debu menumpuk yang mengakibatkan risiko penularan penyakit dapat terjadi. Kelembaban yang kurang memenuhi syarat juga mempengaruhi kualitas komponen rumah, kelembaban yang rendah akan mengakibatkan orang mudah berkeringat dan kelembaban yang tinggi akan menyebabkan kulit kering dan bibir pecah-pecah.

Hasil analisis statistik dengan uji Chi Square didapatkan hasil bahwa, $\rho(0,005)<\alpha(0,05)$ yang berarti ada hubungan antara tingkat pengetahuan dengan kualitas komponen rumah penderita penyakit ISPA. Sedangkan hasil uji Contingency Coefficient didapatkan nilai sebesar 0,403 yang menunjukkan hubungan keeratan antara tingkat pengetahuan dengan kualitas komponen rumah berskala sedang.

Adanya hubungan keeratan antara tingkat pengetahuan dengan kualitas komponen rumah terjadi karena kurangnya pengetahuan penderita tentang kualitas komponen rumah seperti kondisi ventilasi yang kurang sesuai dengan persyaratan, tidak rutin membersihkan debu dalam 
rumah, dan kelembaban yang dimilikinya tidak berkisar antara $40 \%$ $70 \%$. Hal ini disebabkan karena kurangnya informasi yang didapatkan dan ketidak inginan penderita dalam meningkatkan pengetahuan seperti mencari informasi lain dari sumber yang dapat dipercaya

\section{F. Hubungan Sikap Dengan Komponen Rumah Penderita ISPA}

Hasil penilaian tingkat pengetahuan dengan komponen rumah penderita penyakit ISPA di Desa Wage Kecamatan Taman Kabupaten Sidoarjo Tahun 2017 sebagai berikut.

Tabel.6

HUBUNGAN SIKAP DENGAN KUALITAS KOMPONEN RUMAH PENDERITA PENYAKIT ISPA DI DESA WAGE KECAMATAN TAMAN KABUPATEN SIDOARJO

\begin{tabular}{|c|c|c|c|c|c|c|c|}
\hline \multirow[t]{2}{*}{ No. } & \multirow[t]{2}{*}{ Sikap } & \multicolumn{4}{|c|}{$\begin{array}{c}\text { Kualitas Komponen } \\
\text { Rumah }\end{array}$} & \multirow[t]{2}{*}{ Sig. } & \multirow[t]{2}{*}{ Value } \\
\hline & & TMS & (\%) & MS & (\%) & & \\
\hline 1. & Baik & 3 & $50 \%$ & 3 & $50 \%$ & \multirow{4}{*}{0,032} & \multirow{4}{*}{0,344} \\
\hline 2. & Cukup & 9 & $52,9 \%$ & 8 & $47,1 \%$ & & \\
\hline 3. & Kurang & 24 & $85,7 \%$ & 4 & $14,3 \%$ & & \\
\hline & Jumlah & 36 & $70,6 \%$ & 15 & $29,4 \%$ & & \\
\hline
\end{tabular}

Berdasarkan tabel.6 dapat diketahui bahwa penderita yang memiliki sikap baik dengan kualitas komponen rumah tidak memenuhi syarat sebanyak 3 (50\%) karena penderita yang memiliki sikap baik tidak menerapkan kecenderungannya untuk menjaga kualitas komponen rumahnya seperti tidak setuju apabila membuka jendela/ventilasi dipagi hari sehingga udara dalam ruang lembab dan akan menjadi tempat berindukan bakteri. Selain itu tidak setuju apabila menutup mulut ketika batuk maupun bersin karena penderita reflek sehingga tidak menerapkan etika ketika batuk maupun bersih.

Kondisi tersebut menyebabkan udara terkontaminasi oleh percikan ludah dari penderita sehingga orang sehat yang didekatnya dapat berisik tertular penyakit. dan yang memenuhi syarat sebanyak 3 (50\%) karena penderita yang memiliki sikap baik memiliki kecenderungan untuk

menjaga kualitas komponen rumahnya agar sesuai dengan

persyaratan seperti, telah membiasakan untuk membuka jendela/ventilasi dipagi hari karena penderita tahu manfaat cahaya matahari yang mengandung ultraviolet sehingga dapat membunuh kuman penyakit. Serta penderita telah membiasakan menggunakan masker dan menerapkan etika batuk maupun bersin agar orang sehat disekitarnya tidak tertular penyakit.

Hasil analisis statistik dengan uji Chi Square didapatkan hasil bahwa, $\rho$ $(0,032)<\alpha(0,05)$ yang berarti ada hubungan antara sikap dengan kualitas komponen rumah penderita penyakit ISPA. Sedangkan hasil uji 
Contingency

Coefficient

didapatkan nilai sebesar 0,344 yang menunjukkan hubungan keeratan antara sikap dengan kualitas komponen rumah berskala lemah. Hal ini dikarenakan tingkat pengetahuan yang kurang mempengaruhi sikap penderita. Sikap penderita yang kurang akan berpengaruh pada kualitas komponen rumahnya seperti membuka jendela/ventilasi dipagi hari, dan kebiasaan menggunakan masker. Semakin rendah sikap penderita maka kualitas komponen rumahnya juga semakin rendah sehingga akan berisiko terjadinya penularan penyakit ISPA dalam

\section{G. Hubungan Tindakan Dengan Komponen Rumah Penderita ISPA}

Hasil penilaian tindakan dengan komponen rumah penderita penyakit ISPA di Desa Wage Kecamatan Taman Kabupaten Sidoarjo dengan kriteria penilaian TMS = tidak memenuhi syarat dan MS = memenuhi syarat sebagai berikut.

Tabel.7

HUBUNGAN TINDAKAN DENGAN KUALITAS KOMPONEN RUMAH

PENDERITA PENYAKIT ISPA DI DESA WAGE KECAMATAN TAMAN KABUPATEN SIDOARJO

\begin{tabular}{|c|c|c|c|c|c|c|c|}
\hline \multirow[t]{2}{*}{ No. } & \multirow[t]{2}{*}{ Tindakan } & \multicolumn{4}{|c|}{$\begin{array}{l}\text { Kualitas Komponen } \\
\text { Rumah }\end{array}$} & \multirow[t]{2}{*}{ Sig. } & \multirow[t]{2}{*}{ Value } \\
\hline & & TMS & (\%) & MS & (\%) & & \\
\hline 1. & Baik & 1 & $20 \%$ & 4 & $80 \%$ & \multirow{4}{*}{0,002} & \multirow{4}{*}{0,436} \\
\hline 2. & Cukup & 11 & $57,9 \%$ & 8 & $42,1 \%$ & & \\
\hline 3. & Kurang & 24 & $88,9 \%$ & 3 & $11,1 \%$ & & \\
\hline & Jumlah & 36 & $70,6 \%$ & 15 & $29,4 \%$ & & \\
\hline
\end{tabular}

Berdasarkan tabel.7 dapat diketahui bahwa penderita yang memiliki tindakan baik dengan kualitas komponen rumah tidak memenuhi syarat sebanyak 1 (20\%) karena tindakan penderita yang kurang dalam menjaga kualitas komponen rumahnya seperti masih tidur dengan orang sehat dalam satu kamar sehingga orang sehat tersebut berisiko tertular penyakit dan tidak membersihkan rumah secara rutin pada pagi dan sore hari yang akan mengakibatkan penumpukan debu dalam rumah akibat kondisi yang tidak bersih. Selain itu, kebiasaan yang tidak diterapkan dalam membuka jendela/ventilasi pada pagi hari yang mengakibatkan rumah lembab sehingga dapat menjadi tempat pertumbuhan kuman dan yang memenuhi syarat sebanyak $4(80 \%)$ karena penderitak memiliki kesadaran kebiasaan yang baik dalam menjaga kualitas komponen rumahnya seperti telah tidur terpisah dengan orang 
sehat, membersihkan dalam dan luar rumah pada pagi dan sore hari serta telah menerapkan kebiasaan menggunakan masker.

Kondisi ini dilakukan dalam upaya pencegahan penularan penyakit dan penderita dapat memperoleh kesembuhan dengan baik. Hasil analisis statistik dengan uji Chi Square didapatkan hasil bahwa, $\rho(0,002)<\alpha$ $(0,05)$ yang berarti ada hubungan antara tindakan dengan kualitas komponen rumah penderita penyakit ISPA. Sedangkan hasil uji Contingency Coefficient didapatkan nilai sebesar 0,436 yang menunjukkan hubungan keeratan antara tindakan dengan kualitas komponen rumah berskala sedang.
Adanya hubungan keeretan antara tindakan dengan kualitas komponen rumah karena tindakan penderita yang kurang dalam menjaga kualitas komponen rumahnya seperti masih tidur dengan orang sehat, tidak membuka jendela/ventilasi, dan masih jarang dalam membersihkan dalam maupun luar rumah. Kondisi tersebut sangat berpengaruh pada kualitas komponen rumah. Tindakan penderita yang baik harapannya dapat mewujudkan kondisi rumah yang memenuhi syarat. Namun, tindakan penderita yang kurang baik dapat berisiko dalam menjaga kualitas komponen rumahnya sehingga penularan penyakit dapat terjadi.

\section{Hubungan Perilaku Dengan Komponen Rumah Penderita Penyakit ISPA}

Hasil penilaian perilaku dengan komponen rumah penderita penyakit ISPA di Desa Wage Kecamatan Taman Kabupaten Sidoarjo Tahun 2017 sebagai berikut:

\section{Tabel.8}

HUBUNGAN PERILAKU DENGAN KUALITAS KOMPONEN RUMAH PENDERITA PENYAKIT ISPA DI DESA WAGE KECAMATAN

TAMAN KABUPATEN SIDOARJO

\begin{tabular}{|c|c|c|c|c|c|c|c|}
\hline \multirow[t]{2}{*}{ No. } & \multirow[t]{2}{*}{ Perilaku } & \multicolumn{4}{|c|}{$\begin{array}{l}\text { Kualitas Komponen } \\
\text { Rumah }\end{array}$} & \multirow[t]{2}{*}{$\rho$} & \multirow[t]{2}{*}{ Value } \\
\hline & & TMS & (\%) & MS & (\%) & & \\
\hline 1. & Baik & 0 & $0 \%$ & 4 & $100 \%$ & \multirow{4}{*}{0,002} & \multirow{4}{*}{0,551} \\
\hline 2. & Cukup & 10 & $50 \%$ & 10 & $50 \%$ & & \\
\hline 3. & Kurang & 26 & $96,3 \%$ & 1 & $3,7 \%$ & & \\
\hline & Jumlah & 36 & $70,6 \%$ & 15 & $29,4 \%$ & & \\
\hline
\end{tabular}

Berdasarkan tabel.8 dapat diketahui bahwa penderita yang memiliki perilaku baik dengan kualitas komponen rumah tidak memenuhi syarat sebanyak $0(0 \%)$ dan yang memenuhi syarat sebanyak (100\%). Perilaku yang dimiliki penderita sudah baik karena telah menerapkan 
perilaku yang baik dalam menjaga kualitas komponen rumah, seperti luas ventilasi minimal $10 \%$ luas lantai, diletakkan silang atau cross ventilationn, pencahayaan yang diterima sudah baik yaitu $\geq 60$ lux, membersihkan rumah setiap hari secara rutin pada pagi dan sore hari, tidak tidur bersama orang sehat dalam satu kamar dan kebiasaan menutup mulut ketika batuk maupun bersin.

Hasil analisis statistik dengan uji Chi Square didapatkan hasil bahwa, $\rho(0,002)<\alpha(0,05)$ yang berarti ada hubungan antara perilaku dengan kualitas komponen rumah penderita penyakit ISPA. Sedangkan hasil uji Contingency Coefficient

\section{KESIMPULAN DAN SARAN}

\section{Kesimpulan}

1. Perilaku mengenai kualitas komponen rumah termasuk dalam kriteria kurang dengan persentase sebesar $\quad 52,9 \%$. Tingkat pengetahuan penderita mengenai kualitas komponen rumah termasuk dalam kriteria kurang dengan persentase sebesar 56,9\%. Sikap penderita mengenai kualitas komponen rumah termasuk dalam kriteria kurang dengan persentase sebesar $54,9 \%$. Tindakan penderita mengenai kualitas komponen rumah termasuk dalam kriteria kurang dengan persentase sebesar 52,9\%.

2. Kualitas komponen rumah dapat disimpulkan bahwa sebagian besar tidak memenuhi syarat dengan persentase sebesar 70,6\%. Luas ventilasi yang tidak memenuhi syarat dengan persentase sebesar didapatkan nilai sebesar 0,551 yang menunjukkan hubungan keeratan antara perilaku dengan kualitas komponen rumah berskala sedang. Adanya hubungan antara perilaku dengan kualitas komponen rumah disebabkan karena beberapa faktor yaitu tingkat pengetahuan, sikap, dan tindakan yang berpengaruh terhadap perilaku penderita dalam menjaga kualitas komponen rumah. Berdasarkan pengetahuan, sikap, dan tindakan yang baik akan menciptakan perilaku dalam menjaga kualitas komponen rumah yang baik sehingga dapat mengurangi risiko penularan penyakit ISPA serta supaya penderita segera memperoleh kesembuhan.

$74,5 \%$. Pencahayaan yang tidak memenuhi syarat dengan persentase sebesar $70,6 \%$. Kelembaban yang tidak memenuhi syarat dengan persentase sebesar $68,6 \%$. Suhu yang tidak memenuhi syarat dengan persentase sebesar $70,6 \%$. Kepadatan penghuni kamar tidur yang tidak memenuhi syarat dengan persentase sebesar 45,1\%. Kebersihan rumah yang tidak

memenuhi syarat dengan persentase sebesar $62,7 \%$.

3. Ada hubungan antara tingkat pengetahuan dengan kualitas komponen rumah penderita penyakit ISPA dan hubungan keeratan berskala sedang sebesar 0,413 .

4. Ada hubungan antara sikap dengan kualitas komponen rumah penderita penyakit ISPA dan hubungan keeratan berskala lemah sebesar 0,344 . 
5. Ada hubungan antara tindakan dengan kualitas komponen rumah penderita penyakit ISPA dan hubungan keeratan berskala sedang sebesar 0,436.

6. Ada hubungan antara perilaku dengan kualitas komponen rumah penderita penyakit ISPA dan dan hubungan keeratan berskala sedang sebesar 0,551 .

\section{Saran}

1. Bagi Puskesmas Taman

a) Memberikan penyuluhan secara intensif mengenai kesehatan rumah yang meliputi komponen rumah dan perilaku penghuni rumah agar masyarakat mengetahui pentingnya menjaga kebersihan rumah serta membina masyarakat agar membuat rumah menjadi sehat. Hal ini dilakukan untuk pencegahan penyakit, salah satunya penyakit ISPA. Penyuluhan dilakukan minimal satu bulan sekali dengan menggunakan media seperti leaflet. Penyuluhan dapat dilaksanakan di Balai Desa Wage maupun datang ke rumah-rumah.

b) Mengikutsertakan masyarakat untuk membersihkan lingkungan dengan cara kerja bakti secara rutin minimal satu minggu sekali.

c) Melakukan survey secara berkala di setiap wilayah kerja puskesmas agar diperoleh data

\section{DAFTAR PUSTAKA}

Afandi, A.I, 2012. Hubungan Lingkungan Fisik Rumah Dengan Kejadian Infeksi Saluran Pernapasan Akut Pada Anak Balita Di Kabupaten Wonosobo yang akurat mengenai jumlah penderita ISPA dan dapat

dilakukan tindakan-tindakan untuk mengurangi ataupun menurunkan angka kejadian ISPA.

2. Bagi Penderita dan Anggota Keluarga

Diharapkan lebih proaktif mengikuti penyuluhan terutama mengenai kesehatan dan meningkatkan perilaku mengenai faktor risiko penularan penyakit ISPA seperti tidak tidur dengan orang sehat, kebiasaan menggunakan masker, menutup mulut ketika batuk maupun bersin, menjaga kebersihan rumah dengan cara menyapu dan mengepel lantai secara rutin pada pagi dan sore hari, memperbaiki kaca dengan memasang genteng kaca minimal dua buah dalam satu rumah, membuka jendela/ventilasi dipagi hari supaya sinar matahari dapat masuk ke dalam rumah agar suhu dan kelembaban tetap terjaga. Selain itu dapat juga melakukan olahraga rutin dan mengonsumsi makanan bergizi.

3. Bagi Peneliti Lain

Mengembangkan penelitian ini dengan cara mencari variabel lain yang dapat mempengaruhi perilaku dengan kualitas komponen rumah, seperti langit-langit, dinding, lantai, kualitas udara dan lain-lain.

Provinsi Jawa
http://lib.ui.ac.id. 26
2016.

Provinsi Jawa Tengah. 2016. 
Alfaqinisa, Rara, 2015. Hubungan Antara Tingkat Pengetahuan, Sikap, dan Perilaku Orang Tua Tentang Pneumonia Dengan Tingkat Kekembuhan Pneumonia Pada Balita Di Wilayah Kerja Puskesmas Ngesrep Kota Semarang. http://lib.unnes.ac.id. 6 Februari 2017.

Andriani, M., Ade P, 2014. Hubungan Pengetahuan Dan Sikap Ibu Terhadap Kejadian ISPA Pada Balita Di Wilayah Kerja Puskesmas Tigo Baleh Bukittinggi

Tahun 2014. http://ejournal.stikesyarsi.ac.id. 5 Juni 2017.

Ayu, V.O, 2009. Hubungan Antara Sanitasi Fisik Rumah Dengan Kejadian Infeksi Saluran Pernapasan Akut Pada Balita Di Desa Cepogo Kecamatan Cepogo Kabupaten Boyolali.

http://eprints.ums.ac.id. $\quad 26$ Desember 2016.

Catiyas, Embriyowati, 2012. Faktorfaktor Yang Berhubungan Dengan Kejadian

Infeksi Saluran Pernapasan Akut Pada Balita Di Wilayah Kecamatan Gembong Kabupaten Kebumen Jawa Tengah. http://lib.ui.ac.id. 30 Desember 2016.

Chandra, Budiman, 2006. Pengantar Kesehatan Lingkungan. Jakarta. EGC

Dewi, P.S., I Gede W.D., Ni Made M, 2014. Hubungan Faktor-Faktor Sanitasi Rumah Dengan Kejadian Infeksi Saluran Pernapasan Akut Di Wilayah Puskesmas IV Denpasar Selatan. http://poltekkes-denpasar.ac.id. 2 Februari 2017.
Dinas Kesehatan Kota Sidoarjo, 2015.

Profil Kesehatan Kabupaten

Sidoarjo, 2014. Sidoarjo: Dinas

Kesehatan Kota Sidoarjo.

http://www.depkes.go.id. 5

Februari 2017.

Direktorat Jendral PPM \& PL, 2012.

Pedoman Teknis Penilaian Rumah Sehat. Jakarta: Departemen Kesehatan RI

Fillacano, Rahmayatul, 2013. Hubungan Lingkungan Dalam Rumah Terhadap ISPA Pada Balita Di Kelurahan Ciputat Kota Tangerang Selatan. http://repository.uinjkt.ac.id. 6 Februari 2017.

Hayati, Sri, 2014. Gambaran Faktor

Penyebab Infeksi Saluran Pernapasan Akut (ISPA) Pada Balita Di Puskesmas Pasirkaliki Kota Bandung. http://ejournal.bsi.ac.id. 4 Februari 2017.

Imron, Moch, 2011. Statistika Kesehatan. Jakarta: CV Seto Agung

Lingga, R.N., Nurmaini., Devi N.S, 2014. Hubungan Karakteristik Rumah Dengan Kejadian Ispa Pada Balita Dalam Keluarga Perokok Di Kelurahan Gundaling I Kecamatan Berastagi Kabupaten Karo. $\quad$ http://jurnal.usu.ac.id. 23 Januari 2017.

Notoatmodjo, Soekidjo, 2014. IImu Perilaku Kesehatan. Jakarta: Rineka Cipta 